\title{
STUDY ON THE RATIONALITY OF FLOW UNIT DIVISION IN Y OILFIELD
}

\author{
Li Mengmeng', Liu Hongyong ${ }^{2}$, Zhuang Yan ${ }^{3}$, Zhao Jie ${ }^{4}$, Yue Chaoxian ${ }^{5}$, Li Xiaowei ${ }^{6}$, Zhao Xiaojing ${ }^{7}$ \\ ${ }^{1}$ College of Civil Engineering and Architect, Southwest Petroleum University, Chengdu 610500, China \\ ${ }^{2}$ College of Civil Engineering and Architect, Southwest Petroleum University, Chengdu 610500, China \\ ${ }^{3}$ State Key Laboratory of oil and gas reservoir geology and development engineering Chengdu 610500,China \\ ${ }^{4}$ Engineering Management Section, Coal Handan Special sinking Co. Ltd, Handan 056000,China \\ ${ }^{5}$ State Key Laboratory of oil and gas reservoir geology and development engineering Chengdu 610500,China \\ ${ }^{6}$ Institute of foreign languages, Southwest Petroleum University, Chengdu 610500, China \\ ${ }^{7}$ Institute of vehicle and energy engineering, Yanshan University, Qinhuangdao 066004,China
}

\begin{abstract}
Employing the research for and exploitation of remaining oil into division of flow unit in oilfield, especially for which enters extra high water cut stage mining stage oil. This paper selects permeability and porosity as parameters, and uses the cluster analysis method, to divide flow unit in Y oilfield through the SPSS software. Results show that coincidence rate of division of flow units in the liquid producing profile reach $75 \%$, and the load rate of the dynamic water injection reached $82 \%$, therefore it illustrates the division of flow units is reasonable. Meanwhile It provides a reference to improve development effect later.
\end{abstract}

Keywords: Flow Unit, Cluster Analysis, SPSS

\section{INTRODUCTION}

With the oil field developed continuously, oil field has entered the high water cut stage, the remaining oil in the reservoir will be distributed very scatteredly, thus lead to the gradually increasing difficulties in mining. For oil workers, it is a difficult problem to exploit the remaining oil ${ }^{[1]}$. In 1984, Hearn firstly proposed the concept of flow unit, and used a new method to describe the heterogeneity of reservoir which had acquired good effect. With the development of human research, the method of flow unit has become a reservoir characterization and new technology of modeling ${ }^{[2]}$. Reasonable division of flow unit can not only more detailed characterization of formation characteristics, but also can predict the distribution of oil and water in a tank,and It has important guiding significance for studying the further exploitation and the relationship between flow units and production dynamics.

\section{RESERVOIR CHARACTERISTICS}

$\mathrm{Y}$ oilfield is located in the upper part of the rift in southwestern Qaidam Basin in Qinghai Province,which raised a three-stage structure in the convex in North Kunlun faults iron Muli sub region $G$, the physical property of reservoir is good, but most wells are in high water cut stage and especially high water cut stage at present,the middle part of the central production is large, while the volume of the side fluid is small. The average porosity of the oil field is $16.76 \%$, the sample distribution peak is between $15 \%$ and $25 \%$, the average permeability is $18.7 \times 10-3 \mathrm{um} 2$, sample distribution peak is between $100 \times 10-3 \mathrm{um} 2$ and $1000 \times 10-3$ um2. By the statistics, the average saturation of residual oil is $30.83 \%$, the sample distribution peak is at 30 $\sim 35 \%$. According to the distribution, the reservoir physical properties of oil field show the low porosity and low permeability. 
From the first oil wells in 1995 up to now, Y oilfield has been put into the development for 21 years, according to average annual oil production rate, the block has experienced three development stages: low water aquatic rising stage, high water cut and high-speed mining stage, high content of aquatic product decline stage.

\section{FLOW UNIT DIVISION}

Flow unit, also called the hydraulic unit, it refers to the reservoir unit with identical seepage characteristics, it is comprehensive reflection of reservoir petrophysical characteristics, the same flow unit has similar hydrodynamic characteristics and geological characteristics ${ }^{[3]}$. Flow unit division methods mainly have the following several kinds: method of sedimentary facies, rock microscopic pore structure method, analytical hierarchy process (AHP), heterogeneous synthetic index method, multi parameter synthesis method, seismic attribute analysis and so on, according to the data we have, the suitable method should be analyzed and selected for flow unit classification ${ }^{[4]}$. This paper mainly introduces the application of the multi parameter synthesis method in the division of flow units in Y oilfield.

\subsection{Division of flow units in Y Oilfield}

Field data of Y oilfield. Taking into account that the number of oil wells in $\mathrm{Y}$ oilfield is small and the data is limited, so we directly choose to cluster all the data to divide. Here we select the known porosity and permeability as the dividing parameters.

In the clustering process, we used the FOR WINDOWS SPSS16.0 software. The method of the middle distance of the standard Euclidean distance are used in clustering.
By clustering, all datas were divided into four categories (Table 1).

Table 1. Flow Unit Classification

\begin{tabular}{c|c|c|c|c}
\hline & 1 & 2 & 3 & 4 \\
\hline Porosity (\%) & 28.9 & 27.5 & 25.7 & 20.7 \\
\hline Permeability (md) & 818.38 & 466.12 & 237.54 & 53.34 \\
\hline
\end{tabular}

\subsection{Clustering Effect Analysis}

As can be seen from the table 2,N1 clustering has 828 groups of data, The clustering rate is $100 \%$, there is no data loss. Therefore, it can be known that the effect of classifying is good.

Table 2. Case Processing Summary

\begin{tabular}{c|c|c|c|c|c}
\hline \multicolumn{6}{c|}{ Cases } \\
\hline \multicolumn{2}{c|}{ Valid } & \multicolumn{2}{c}{ Missing } & \multicolumn{2}{c}{ Total } \\
\hline $\mathrm{N}$ & Percent & $\mathrm{N}$ & Percent & $\mathrm{N}$ & Percent \\
\hline 828 & $100.00 \%$ & 0 & $0.00 \%$ & 828 & $100.00 \%$ \\
\hline
\end{tabular}

\subsection{Flow Unit Classification Criteria}

Based on the cluster analysis and the quantitative calculation of single well flow unit, we set up the classification standard of the flow unit in $\mathrm{Y}$ oilfield (Table 4), according to the cluster result table (Table 3 ) and the related data.

Table 3. Number of Cases in each Cluster

\begin{tabular}{|c|c|c|}
\hline \multirow{4}{*}{ Cluster } & 1 & 79 \\
\hline & 2 & 123 \\
\hline & 3 & 213 \\
\hline & 4 & 413 \\
\hline \multicolumn{2}{|c|}{ Valid } & 828 \\
\hline \multicolumn{2}{|c|}{ Missing } & 0 \\
\hline
\end{tabular}

Table 4. Classification Criteria of Flow-Unit In Y Oilfield

\begin{tabular}{c|c|c|c}
\hline Type & porosity $(\%)$ & $\begin{array}{c}\text { permeability } \\
\left(10^{-3} \mu \mathrm{m}^{2}\right)\end{array}$ & sedimentary microfacies \\
\hline Class I (super) & More than 28.36 & More than 655.61 & $\begin{array}{c}\text { Mainly in the mouth bar and the } \\
\text { underwater diversion channel }\end{array}$ \\
\hline Class II (good) & 26.89 to 28.36 & 364.95 to 655.61 & $\begin{array}{c}\text { Mainly in the underwater diversion } \\
\text { channel, mouth bar and underwater } \\
\text { distributary interchannel }\end{array}$ \\
\hline
\end{tabular}




\begin{tabular}{c|c|c|c}
\hline & & & \\
\hline Class III (general) & 24.6 to 26.89 & 146.53 to 364.95 & $\begin{array}{c}\text { Mainly in the underwater channel and } \\
\text { sheet sand }\end{array}$ \\
\hline Class IV (poor) & Less than 24.6 & Less than 146.53 & $\begin{array}{c}\text { Mainly in the underwater diversion } \\
\text { channel and mouth bar }\end{array}$ \\
\hline
\end{tabular}

According to the actual situation of $\mathrm{Y}$ oilfield and the field data,the criteria for the classification of flow unit in $Y$ oilfield is determined through the SPSS software division, speaking from the geological structure, sedimentary microfacies have no obvious difference among them,it is classified mainly according to the permeability and porosity. It is obvious that the reservoir conditions of class I and class II flow units are better than that of class III and IV flow units.

\subsection{Characteristics of Various Types of Flow Units}

Class I flow unit (excellent): based on fine sandstone,its permeability is at $655.61-992.28 \times 10-3 \mu \mathrm{m} 2$ and the average is $818.38 \times 10-3 \mu \mathrm{m} 2$, its porosity is at $28.36-29.4 \%$ and the average is $28.91 \%$. The pore connectivity is really good with pore type being primary intergranular pore. The main types of sedimentary microfacies are the main body of the mouth bar and the underwater diversion channel.

Class II flow unit (good): based on the fine sandstone ${ }^{[5]}$ and silty sandstone, the permeability of in it is at 364.95-655.61 $\times 10-3 \mu \mathrm{m} 2$ and the average is $466.12 \times 10-3 \mu \mathrm{m} 2$, its porosity is at $26.89-28.36 \%$ and the average is $27.5 \%$. The pore connectivity is good, and the pore type is mainly composed of primary intergranular pores. The main types of sedimentary microfacies are underwater diversion channel, mouth bar and underwater distributary interchannel.

Class III flow unit (general): mainly based on fine sandstone, its permeability is at $146.53-364.95 \times 10-3 \mu \mathrm{m} 2$, and the average is $237.54 \times 10-3 \mu \mathrm{m} 2$, the porosity of it is at $24.6-26.89 \%$ and the average is $25.7 \%$. The pore connectivity is general, the pore structure is mainly small pore throat. The main types of sedimentary microfacies are underwater channel, sheet sand.
IV type flow unit (poor): mainly based on powder sandstone, it has the fine lithology and high shale content, so the permeability is low, generally between the $0.18 \times 10-3 \mu \mathrm{m} 2$ and $146.53 \times 10-3 \mu \mathrm{m} 2$, the average is $53.34 \times 10-3 \mu \mathrm{m} 2$, the porosity is at $7.8-24.6 \%$ and the average is $20.7 \%$. The pore connectivity is poor, the pore structure is mainly small pore throat. The main types of sedimentary microfacies are underwater diversion channel and mouth bar.

\section{THE RATIONALITY OF FLOW UNIT}

Since the flow unit is a reservoir unit with the consistent characteristics of seepage flow, then the same types of flow unit are bound in the reservoir and have a common representation in reservoir percolation characteristics ${ }^{[6]}$ of production wells and injection wells, or the the differences of seepage characteristics existed in different kinds of flow units should be directly reflected in the reservoir and production dynamic of production wells and injection wells [7]. According to the results of $\mathrm{Y}$ oil field division, it is known that, followed by class III, most of them belong to the class IV flow unit, while it's just a small part of it as for class I and class II which have the better development.

\subsection{Division of Flow Units from the Liquid}

\section{Production Profile}

Y oilfield had 32 wells injection profile test in 15 production wells, 201 small layers were tested (the well layer will not be counted repeatedly), of which the only 71 are divided into flow cell types, while 130 small layers are not partitioned flow unit. The result of partition is shown in figure 1. 


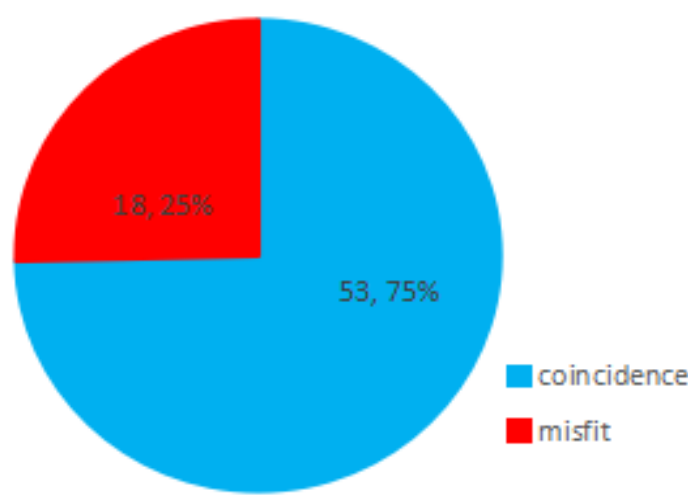

Fig 1. Extent Consistent For Flow Unit

According to the statistics of division of the flow unit of the 71 small layer, and it can be seen that the flow unit types are in agreement with output status of small level of the 53 small layer from the figure 1 , accounting for $74.6 \%$, while only 18 small layers do not match, accounting for $25.4 \%$. The situation that the flow of unit type is in accordance with the small layer output condition, just refers that the mainly produced liquid layer in the same wells is class I or class II flow unit layer; secondary liquid layer is the flow units in category III; micro production liquid layer or immobile layer is class III and class IV of flow units, output status among them only has the relationship of relative high or low, and quantitative relationship between the type of flow unit and fluid producing intensity level is no strict, but the general relationship is quite normal. For example, most of the immobile layers are the class IV flow unit, and the minority is class III flow unit, there are very few cases that class I and class II mobile units are for the non moving layer.

\subsection{The Flow Unit Division Seen From The}

\section{Dynamic View Of Water Injection Well}

From the point of view of the profile of six water injection wells in Y oilfield, A total of six wells were tested in 23 wells with a total of 94 small layers (the well layer will not be counted repeatedly), of which 39 small layers are divided into flow unit types, but 55 layers are not partitioned flow units. The paper counts up 39 small layers divided into flow units, the statistical figure is shown in figure 2.

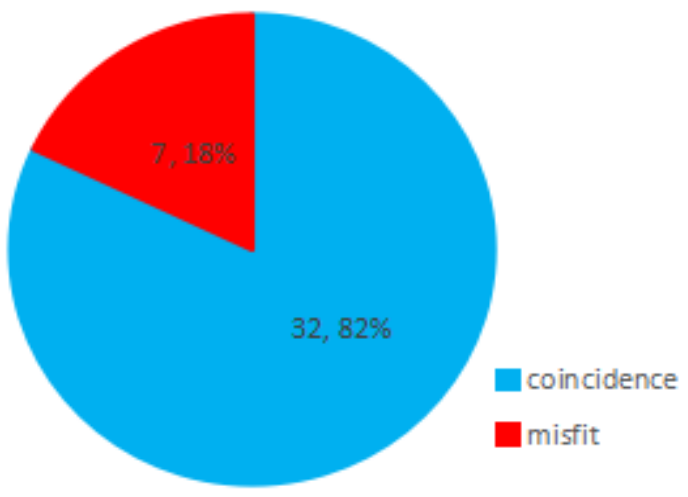

Fig 2. Extent Consistent For Flow Unit

From Figure 2 ,it can be clearly seen the 32 small layers that the flow unit is in agreement with the water absorption of the small layer, accounting for $82.1 \%$, while only 7 small layers do not match, accounting for $17.9 \%$. Like wise, The situation that the flow of unit type is in accordance with the small layer suction condition, just refers that the mainly water accepting layer in the same wells is class I or class II flow unit layer; secondary water accepting layer is the flow units in category II and category III; micro water absorption layer or non absorbent layer is class III and class IV of flow units, water absorption status among them only has the relationship of relative high or low, and quantitative relationship between the type of flow unit and injection index is no strict, but the general relationship is quite normal. For example, most of the non absorbent layers are the class IV flow unit, and the minority is class III flow unit, there are very few cases that class I and class II mobile units are for the non absorbent layer.

\section{CONCLUSION}

This article uses the method of multiparameter clustering analysis, the reservoir of the study area is divided into 4 types of flow units by SPSS software with the permeability and porosity being reference variables, various types of flow units have certain differences in the lithology, physical property and sedimentary type. The reservoir properties of class I and class II are relatively good, mainly based on fine sandstone, the permeability and porosity are relatively larger, the pore connectivity is good, sedimentary microfacies types are mainly under the water diversion channel, mouth bar and so on. There is a large number of flow units in class III and class IV, but the performance is relatively poor, mainly 
based on siltstone, and they have fine lithology and high shale content, the permeability and porosity are low, the main types of sedimentary microfacies are the diversion channel.

Through the statistics of the yield, class I and class II reservoir not only have better performance, but also have the relatively high yield, while the fluid production of class III and class IV reservoir is relatively low, which is also consistent with the four types of flow units in this paper. From the point of view of water injection profile analysis, the main absorbent layer in each well is class I and class II flow unit, the non absorbent layer is mostly a class IV flow unit, which shows that the division of the flow unit is reasonable and it is of great practical significance.

\section{REFERENCES}

[1] Liu Q Y, Research progress of flow unit[J]. Earth science progress, 2000, 15(3): 303 306.

[2] Xiong G J, Liu L. Based on division of flow units of reservoir configuration and the impact on the development [J]. Journal of southwest petroleum university (natural science edition), 2014 01:107-114.

[3] Yao G Q, Li L W, Sun S R. Sandstone reservoir composition quantitative analysis [J]. Journal of geological science and technology intelligence, 2001, 20 (1) : 35-38.

[4]Yuan C P. Oil and gas reservoir flow unit study review [J]. Journal of geological science and technology intelligence, 2006, 12 (4) : 202-204.

[5] Zhang J. Clastic flow unit study progress and understanding [J]. Journal of China offshore oil and gas (geology), 2003, 8 (4) : 252-254.

[6] Yue D L. Clastic rock reservoir flow unit study progress

[J]. Journal of Chinese scientific papers online, 2008, 35 (11) : 45-48.

[7]Wu S H. Continental new ideas in the study of reservoir flow unit [J]. Journal of sedimentary, 1999, 15 (2) : 28 and 29. 